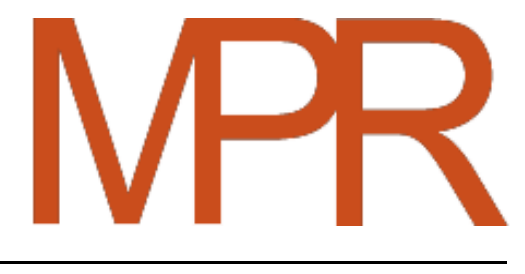

Music Performance Research

Copyright (C) 2020

Royal Conservatoire of Scotland

Vol.10

38-56

ISSN 1755-9219

\title{
Collaborative learning and choral confidence: the role of peer interactions in building confident amateur choirs
}

\author{
Michael Bonshor \\ University of Sheffield
}

\begin{abstract}
This article describes some of the collaborative processes that take place within adult amateur choirs, and demonstrates some associations between group dynamics, peer learning and the development of choral confidence. Three focus groups and 16 individual interviews provided 40 hours of verbal data. The research aims were: to explore the lived experience of amateur choral singers in relation to their confidence levels; to identify some of the factors affecting singers' confidence in their vocal skills and choral performance ability; to use the data to extrapolate strategies designed for managing confidence issues amongst amateur choral singers. Data was collected during semi-structured interviews and focus groups with amateur singers. The superordinate themes, which emerged from the data, included collaboration and teamwork, reciprocal peer learning, and the contribution of unofficial team leaders to effective learning and performance. All of these factors were reported as increasing individual and collective confidence levels. The findings highlight the role of peer interactions and social learning in developing the confidence of choral singers, and suggest ways in which conductors might optimize these interactions to build confidence during choir rehearsals and performances.
\end{abstract}

KEY WORDS: choirs, choral singers, confidence, self-efficacy, conducting 


\section{INTRODUCTION}

There is increasing evidence for the personal and social benefits of participating in group singing, including: enhanced general health and well-being (Mellor, 2013); physiological improvements (Beck et al., 2000; Kreutz et al., 2004); psychological well-being and mood enhancement (Clift \& Hancox, 2010; Judd \& Pooley, 2014); and social cohesion (Faulkner \& Davidson, 2006; Parker, 2010). Additionally, research has demonstrated that ensemble singing has therapeutic outcomes for adults with physical or mental health problems (Eades \& O'Connor 2008; Dingle et al., 2013), and reduces social isolation (Bailey \& Davidson, 2002, 2005; Creech et al., 2013). However, there is also evidence that a significant number of adult amateur singers are adversely affected by confidence issues, which can have negative effects upon their experience of choral singing, and can limit the level and extent of their participation (Bonshor, 2002). Where low confidence affects participation, the personal wellbeing benefits and social capital (Ruud, 2013) derived from choral singing are less likely to be fully realized.

Within psychological frameworks, confidence-related issues have generally been expressed in terms of self-efficacy (Bandura, 1977). In performance studies, the terms confidence and self-efficacy have often been used interchangeably (Vealey et al., 1998), and I have followed this convention. Some of the particular challenges of learning music and singing in public performances are epitomized by the following definition of self-efficacy:

The belief in one's competence to tackle difficult or novel tasks and to cope with adversity in specific demanding situations. (Luszczynska et al., 2005, p. 81)

In studies of music students, it has been established that high self-efficacy is associated with high achievement (McPherson \& McCormick, 2006) and that perceived efficacy is often "the best predictor of actual performance" (McCormick \& McPherson, 2003, p. 37). Despite these findings, research into musical confidence and the potential applications of selfefficacy theory have been limited:

\footnotetext{
Given the enormous body of evidence showing the power of self-efficacy's influence on academic achievement, it is surprising how few studies have applied this theoretical framework in music, an area of learning that places great physical, mental and emotional demands on musicians. (McPherson \& McCormick, 2006, p. 332)
}

A handful of previous studies have focused on self-efficacy amongst highly trained university and conservatoire students (McCormick \& McPherson, 2003; Nielsen, 2004; Ritchie \& Williamon, 2011). In contrast, adult amateur singers have been under-represented in musical self-efficacy research, despite comprising the largest cohort of participants involved in music-making in the West (Stebbins, 1996; Sundberg, 1987). Similarly, very little research has examined the collective aspects of self-efficacy in the context of amateur choral performance.

Among amateur singers, the social and psychological processes inherent in group singing activities, as well as baseline confidence levels, may differ from those found in advanced tertiary level music students. Amateur singers have usually received less musical and vocal training than university and conservatoire students, and it has previously been found that relevant training can significantly improve singers' confidence levels (Bonshor, 
2002).

"Confidence is both a personal and a social construct" (Pajares, 1996, p. 567), so a sense of collective efficacy can develop within many different kinds of organizations. This can have a profound effect on the motivation, resilience and achievements of individuals and the group as a whole (Bandura, 2000). In sports psychology research, the players' beliefs in team capabilities have been found to have a strong impact on motivation and performance standards (Greenlees et al., 2000; Bray, 2004; Chow and Feltz, 2008). High levels of perceived group efficacy have a positive influence on the emotional responses of team members and reduce performance anxiety (Greenlees et al., 1999). These aspects of collective efficacy may suggest some practical applications in the amateur choral environment. However, this has not been evidenced in previous research on collective musical efficacy, which has tended to focus on groups of advanced, tertiary level music students (Hendricks, 2014) rather than upon adult amateur singers, who usually have different levels of formal training and motivations for participating in group singing as a leisure activity.

Self-efficacy is obtained from personal, goal-referenced judgements grounded in the individual's subjective perception of their own performance, and this perceived self-efficacy can be changed (Bong \& Skaalvik, 2003). According to Bandura (1977), the three main approaches to increasing self-efficacy are: gaining direct personal experience of successful performance ("task mastery"); obtaining vicarious experience (learning from observing others); and receiving verbal encouragement. If self-efficacy is strengthened through using these strategies, further improvements in performance subsequently take place. This results in a virtuous circle of task mastery, motivation, effort, successful performance and increased self-confidence. The findings presented in this article relate to all three of Bandura's suggested approaches to increasing self-efficacy, with some potential implications for conductors of amateur choirs.

\section{RESEARCH AIMS}

In an earlier study (Bonshor, 2002), I had found that confidence-related concerns were common amongst adult amateur singers, and that these concerns had a negative impact upon their enjoyment of participating in choral performance and (for some singers) upon the extent and level of their participation. As previously mentioned, there is an increasing amount of research evidence demonstrating the wellbeing benefits of choral participation. However, it would seem that, if either participation or enjoyment of performance is limited due to confidence issues, these wellbeing benefits may be less accessible to singers. I therefore surmised that exploring the factors affecting confidence levels amongst adult amateur singers might yield results which could suggest ways to help singers to make the most of the wellbeing benefits of choral singing.

Despite the large population involved in amateur choral activities, there has been a limited amount of research into musical self-efficacy amongst these performers. This research project was therefore designed to extend knowledge in this area, with the following aims:

- To explore the lived experience of amateur choral singers in relation to confidence levels 
- To identify some of the factors affecting singers' confidence in their vocal skills and choral performance ability

- To use the data to extrapolate strategies designed for managing confidence issues amongst amateur choral singers.

\section{RESEARCH DESIGN AND METHODS}

In order to provide a counterbalance to the relative under-representation of adult amateur choral singers in previous studies, I selected a research design in which the singers' reported experiences, feelings, opinions and perceptions could be prioritized. Qualitative methods are commonly accepted as appropriate for researching unquantifiable phenomena, such as the beliefs, feelings, expectations, perceptions, and emotions of "real people in their everyday lives" (Bogdan \& Taylor, 1975, p. 5). A series of semi-structured, in-depth interviews with 16 amateur singers, and three focus groups with a total of 18 participants, were used to explore the participants' experiences of group singing, and their responses to these experiences. This approach was intended to allow the participants' voices to be heard and understood as clearly and directly as possible (Patton, 1991).

During the three focus group sessions, participants introduced some of the major emergent concepts and provided rich data; the interactive group processes prompted accounts of both similar and contrasting experiences. It was intended that the group setting would reduce the researcher's influence on the interview process and increase internal validity (Frey \& Fontana, 1991; Madriz, 2000). Earlier focus group studies in the performing arts (Faulkner \& Davidson, 2006; Radbourne, Johansson, Glow, \& White, 2009) provided valuable exemplars for this project.

Sixteen semi-structured interviews with individual choral singers were subsequently completed. These were based on open questions within a flexible interview schedule, allowing the participants to play a strong part in directing the encounter, and freeing the conversations to enter areas that I had not necessarily foreseen, but which were very relevant to the research questions (Smith 1995). This format allowed themes to emerge spontaneously from the conversations with the singers rather than from any preconceived themes or hypotheses.

Each focus group and interview lasted for at least two hours, so that over 40 hours of recorded verbal data were gathered. Each participant completed a background information form, which provided statistical and contextual data. Internal validity was reinforced by post-interview member checks, which ascertained whether or not the participants agreed with my interpretation of their input, and also whether an appropriate level of emphasis had been placed upon each of the emergent themes. This aspect of the research design, alongside an iterative process of reflectivity and reflexivity (Janesick, 1999), was intended to reduce the possibility of researcher bias.

The interview data underwent a process of interpretative phenomenological analysis, which allowed the researcher to take into account some of the nuances of interview data relating to the participants' personal experience, individual belief systems and subjective perceptions (Smith et al., 2009).

In the interests of transparency, the role of the researcher in this particular project is hereby defined as a researcher-practitioner, with experience as a choral and orchestral 
conductor of professional and amateur ensembles. The participants in the focus groups and half of the individual interviewees had, at some stage, sung in one of the many choirs that I have conducted. However, all participants had experience of singing in a wide range of choirs with other conductors and the data reflected their diverse experience. Where participants referred to their experience with the author as conductor, this has been made clear in the wording and contextual information provided in the transcriptions.

It is also necessary to acknowledge the dichotomous role of the researcher who (as participant observer, interviewer, and focus group facilitator) is actively involved in the research setting, but who also "removes him or herself from the situation to rethink the meanings of the experience" (Maykut \& Moorhouse, 1996, p. 25) and to contextualize the findings in relation to previous research literature and relevant psychological frameworks in this area.

\section{Participants}

A total of 34 amateur singers participated in this study; 16 took part in individual interviews and 18 took part in the focus groups. There was an equal number of male and female singers, and no significant gender-based differences emerged from the data regarding the main research topics. At the beginning of the study, recruitment was based on "convenience sampling", (Corbin and Strauss, 2008), as participants were initially invited to take part via personal contacts. The pool of participants was then widened using a "snowballing" process (Goodson and Sikes, 2001). Purposive sampling ensured that most interviewees were highly experienced choral singers, who had sung in several different choirs and worked with a number of different conductors, so that they could make a knowledgeable and meaningful contribution to the research. However, participants were not recruited according to whether or not they had experienced any confidence issues related to their choral singing.

All except two of the singers had over five years of choral experience, and 23 participants had over 15 years of relevant experience. This level of experience is reflected by the age group of the majority of the participants. Eighteen participants were over 60 years old, 15 participants were aged between 41 and 60 years, and one participant was in her mid-thirties. Between them, the participants had experienced a wide range of different types of choral singing, including community choirs, chamber ensembles, operatic and choral societies, and musical theatre choruses. Most participants had experience of singing in several different group contexts, and often belonged to more than one choir at a time. This breadth of experience among the participants means that their reported "lived experience" is not limited to one particular genre of amateur group singing, and that the findings and implications may be relevant in a variety of amateur choral settings. The participants were able to report on their experiences of singing with choirs throughout the UK, including ensembles in Wales, Cornwall, Devon, Lancashire, Yorkshire, Leicestershire, Nottinghamshire, Lincolnshire, Rutland, Surrey and Hampshire. This helped to ensure that the research findings were not unduly affected by local trends; during my own experience in this field, I have observed that choir leaders are sometimes influenced by the working practices of others in the same geographical area. Apart from one interviewee, all of the research participants had experience of performing with several different choir leaders; in fact, 13 participants had performed with more than six conductors. This aspect of the sample took into account the likelihood that different conductors will have different 
approaches to working with amateur singers.

The participants were defined as amateur singers if their singing activities took place in their leisure time and, even if forming a significant part of their lives, did not contribute to their income. Although the research participants' experience of choral singing was extensive, and they all demonstrated a strong commitment to this leisure pursuit, only two interviewees had any formal musical education beyond secondary school, and many participants had received no in-depth musical training during their school years. All participants have been anonymized in the following quotations, and are identified by a number, followed by the page number of the transcription from which the extract is taken. The letter " $\mathrm{S}$ " indicates a quotation from a singer participating in an individual interview, and "FG" represents a focus group extract.

\section{FINDINGS}

From the data analysis, several superordinate themes emerged but it is beyond the scope of this article to detail them all here. The current paper will concentrate on the superordinate theme of "choral group dynamics". This encompasses a range of peer interactions (i.e., the ways in which singers in amateur choirs interact with each other), and how these interactions affect their confidence levels relating to their group singing activities. Subordinate themes include the "importance of group dynamics", "social relationships", "teamwork", "reciprocal peer learning", and "the role of informal team leaders", all of which contributed to the singers' confidence in the choral context.

\section{Cohesion, community and collaboration}

In order for the singers to feel confident during rehearsals and performances, they largely agreed that they needed to feel a sense of community in a cohesive, collaborative group. In every focus group and individual interview, the research participants emphasized the value of the choir as a collective body, and often discussed their choral engagement in relation to the social benefits:

One of the reasons why we all enjoy it so much is because we have fun together. We're

like-minded people, so it's a social thing as well as really enjoying the singing. FG1.H.5

Many interviewees highlighted social cohesion and a sense of community as being among the main benefits of choral participation. The words "camaraderie", "comradeship" and "community" were commonly used by participants when discussing this aspect of group singing:

All being together - a sort of camaraderie about it. It's good, 'cause you feel...It's like surfing on the crest of the wave, all four of you [tenors]. And also the whole choir, all together, you know. S6.3

In some cases, this sense of social cohesion extended beyond the choral environment and was a valuable source of support, both within the choir and in their everyday lives:

One of the words we used to use in the male voice choir was comradeship. And if somebody was in trouble [...] the choir was there. It was so, so tight. And I believe that builds good performances. I think that builds a good choir, personally. S8.32

The beneficial effects of community spirit upon performance quality were appreciated by many singers, and were often seen as integral to the structure, function and continuance 
of the choir:

We have this great sense of community... I have a theory that, for a choir to survive, it's bigger than just the people in it. It's the creation of quality and of grace and of sharing all this stuff, which comes from the order of the choir. S13.24-25

For many participants, the sense of community and camaraderie gained from choral singing increased their confidence in their own performance capabilities:

Personally, [confidence] comes from the other chaps who I sing with. That gives me the confidence. S11.25

The testimony of these amateur singers directly illustrates the social benefits of ensemble singing indicated in earlier research (Bailey \& Davidson, 2002, 2005; Dingle et al., 2013; Faulkner \& Davidson, 2006), and demonstrates the confidence building effects of these social aspects of choral participation.

\section{Teamwork}

Interviewees also commonly discussed the particular satisfaction derived from achievements based on team effort. Some interviewees related their experience of singing in a choir to other shared work-related or communal projects in their lives:

Some of the best projects I've been in have been as part of a team with a common goal...And that's what a concert is. It's a project team coming together to do a one-off thing. And you work on your pieces and you rehearse, and then you deliver on the day. S5.53

Feelings and experiences related to team spirit, cohesion and collective achievement were specifically cited as contributory factors in building confidence during performance:

I thought we sang as a choir the best that we sang. So that gave you confidence that you were sort of...everybody seemed to be on the right wavelength - we were gelling and things like that. S3.1

The concept of the choir as a team was further developed when participants talked about their feelings about feedback from audiences. Many interviewees emphasized that, as choral singers, they are evaluated on the performance of the choir as a whole. This sense of the performance as a "group effort" (S3.41; S4.18) can add to individual self-confidence. The knowledge that choral singers are not generally being judged on their personal performance, and that the responsibility for the performance is shared, can take the pressure off the individual:

If you make a slip, just miss a word or something, [nobody's] going to notice. But if as a body, or a group, or a section within the choir, you make a mistake, it might get noticed. S6.11

Poor performances from individual choral singers or sections may sometimes have a negative effect on the performance of the choir as a whole. Equally, performance satisfaction, perceived task mastery, and collective and individual efficacy were reported as being increased when the choir performs well, as a team:

When we're all together, and we do make a good sound - which we do - that makes me feel good. It's definitely a feel-good factor with the choir. S1.48

The challenge of listening to each other, and becoming integrated into the choral team, 
was recognized by some singers during one of the focus groups:

It is a team thing [pause while all members of the focus group express agreement], and you need to be able to listen, but it takes a lot of practice to be able to listen to the other people and still sing your part [all agree] FG2.K.54

On the whole, participants reported co-operative musical relationships with their fellow singers, and appreciated the opportunity to work as a team:

It's very fulfilling and it's nice to be in a close harmony group [...] where you need to be very aware of what the other people are doing. You're not there to be a soloist - you're there to listen to other people and blend in with everybody. FG1.X.2

\section{Peer Interactions}

There was general agreement that confidence was derived from peer interactions, and from the sharing of skills and experience:

That's the thing with our group - we all encourage each other. We all have different strengths, haven't we? [...] And that helps your confidence. FG1.H.11

During all three focus groups and all 16 individual interviewees, positive interactions between singers were discussed at length. Sharing mutual encouragement and moral support was a significant factor in developing confidence:

You know [soprano] stands next to me and I'm ever so nervous...saying, "I'll never be able to do this-I can't do this", you know...But [she] always encourages me...she's encouraging me all the time. FG1.N.11

Support from fellow choir members ranged from verbal encouragement during rehearsals and performances to congratulation and affirmation after the event:

When we went up to do the [...] "Sloop John B" and I was like, "I'm dreading this, I'm absolutely dreading this, because I know I just don't know this". And [fellow alto] was like, "You'll be fine!" And then we came back and I went, "I did it!" [...] And she went, "Ooh, well done!" S1.51

Positive feedback from peers, especially from singers who were perceived as being notably skilled or experienced, was seen as particularly effective for building confidence:

I was querying a note or something, and [fellow singer] said, "You ought to have the courage of your convictions". She was being quite complimentary, in other words, you know - I was doing fine, I just needed to believe in it. S7.8

These interactions are integral to the creation of a supportive learning environment and help to improve individual self-efficacy for singing. Verbal encouragement from fellow choir members confirms a singer's integration into the choral "team", as well as validation of their individual vocal ability:

I think they can make you feel positive...If someone does a really good job, then we'll say they've done a really good job... And the recognition coming from others, and you're sort of like, "Yeah, they think it's OK too! I'm not completely doolally". It's a genuine thing. S10.18

These findings reflect Bandura's (1977) proposal that the strongest role models are those who are in similar situations to the individual, and that verbal encouragement is most effective in boosting self-efficacy if the feedback comes from someone who is perceived as 
having some knowledge and experience of the shared activity.

\section{Trust and reciprocal peer learning}

Trust was seen as essential to facilitating a collaborative environment in which effective learning and confidence-building can take place:

It's confidence in who you're performing with. Knowing that they know, and that they're going to do what they should. S12.25

Conversely, lack of trust amongst fellow singers had a negative impact upon affective responses and confidence levels:

I'm a person that probably would tend to worry if somebody's a bit shaky, you're thinking, "Ooh, is it all going to fall apart any minute?", and you're a bit tense because of that. S6.1

Positive peer interactions often led to feelings of sufficient trust and security to accept guidance and constructive criticism from respected team members, and this aspect of teamwork had a confidence-building effect within the ensemble:

The rapport is good, and that's important as well, isn't it? So why should we criticize? 'Cause we all get it wrong. [...] We're not there to criticize each other, we're there to help each other. $\mathbf{S 8 . 3 0}$

An experienced bass introduced the concept of choral learning as a multidirectional process, which is shared by the singers, rather than being purely dependent upon unidirectional communication dispensed by the conductor:

I know his voice. I trust him. We like each other! [laughs] This is a tenor. And I nudge him and say, "You made a balls there!", or something like that [laughs]. And he does to me as well, I may hasten to add. It's a two-way traffic. That's what learning's about, isn't it? S13.16

This illustrates the importance, for amateur choral singers, of learner to learner feedback based on trust, goodwill and familiarity. This theme of reciprocal peer learning was developed and contextualized in other interviews:

Certainly in places like summer schools and workshops, everybody supports everybody else, in a sort of a quiet way. They're watching you and learning from you, and you're watching them and learning from them. And it's all very comfortable, and confidenceboosting. S16.12

Practical, musical and technical help from peers was commonly reported as being provided during performances, as well as while learning and rehearsing. Peer support included reminders of words, melody and harmony lines:

I often find myself turning to [bass] and saying [whispers], "How does this one go?" And he whispers back, saying, "I don't know. Ask him!" [points to where next singer stands]. S4.19

\section{Choral team leaders}

As well as discussing the general, multidirectional learning between choir members, all three focus groups and the majority of individual interviewees described their reliance on support from specific neighbouring singers. One of the focus group participants directly addressed a fellow singer, acknowledging her colleague's help with pitching, and 
recognising the sense of security that this gives her:

You're very confident in what you're singing [to fellow alto], and you will always start on the right note. I always feel that maybe I won't, so if you're standing next to me, or [alto] is standing nearby, then I know that if I do falter at any time, I can get back on track because I can hear somebody who's singing the right note. FG2.K.41

Participants often identified particular "key" singers who were perceived as able to lead by example, and their musical guidance and moral support was felt to contribute towards the confidence of the singers around them:

We've done it quite often...sort of lean in, and we know that [alto] will have the right note. We know when one another has gone a bit wrong and we chivvy one another along. FG1.N.35

One of the participants found a strong metaphor to illustrate the powerful impact that certain individual singers can have:

It's very helpful to have a rock, you know, within the group, that you can latch on to...I think you do need that someone in a particular piece, who knows what they're doing. [...] It gives you confidence. FG3.C.16

This theme of identifying and depending upon certain singers who become figurative "rocks", or team leaders, continued in 11 of the 16 individual interviews. These informal team leaders were not elected in any way but became known as singers who could be relied upon to contribute to the confidence of their vocal section or, quite often, the whole choir. Peer-identified team leaders are sometimes more experienced singers or longer-serving choir members, but not always. Their position as a role model, unofficial team leader or informal mentor is usually based on their skill level in various areas, such as sight reading, pitching notes, remembering lyrics and/or being confident about musical entries. Another focus group participant directly acknowledged the confidence building support of a fellow singer:

Actually, having you there [to bass] in the choir really helps me. It really does. It helps me just maintain...get the right notes or whatever, 'cause I'm subject to straying, and you're consistent. FG3.15

A singer's own perceived self-confidence can also have a positive impact on their neighbours, partly due to emotional contagion (Bonshor, 2014, 2018; Falkenberg et al., 2008), and partly due to positive modelling, both in musical and affective terms:

It does make a difference who I stand next to... If someone's really confident and can hold the note, then I will hold my notes as well. $\$ 4.10$

Although these roles are not part of the formal organisation of the amateur choir, as section leaders are in a professional orchestra (Davidson, 1997), there is a tendency for more self-assured singers to act as a spokesperson for their vocal section. Reassurance may be gained from the realization that even the unofficial team leader sometimes needs extra assistance from the conductor:

There are occasions when we're rehearsing and [team leader] will say, "Can we do so and so again because we're struggling with that bass part", and I think to myself, "Well, if [he] is struggling then I'm bound to be struggling as well". S11.21

Some singers suggested that these choral team leaders often seem to be unaware of 
their informal leadership position or may be reluctant to take credit for their influence within the section or the choir as a whole:

I suppose to a great extent we do look to [first bass]. He's been doing it a long time and he's got a damn good bass voice. And so, consequently, you tend to, I suppose, think of him as our leader, if you like. He would never want to sound that way. If you said it to him, he'd say, "Oh, don't be so damn soft!" He wouldn't see it that way. S11.20

Singers who did realize that they had been informally identified as unofficial team leaders reported deriving some of their own confidence from the knowledge that they contribute to the choir in this way, and from peer recognition of their skills. It therefore seems that, within amateur choral ensembles, the confidence building nature of the informal team leader/follower dyad is reciprocal:

\begin{abstract}
Amongst my group of singers [...] there are varying degrees of understanding of musicality, shall we say, so I like to know that at least a few of us have got it...'Cause I'm quite bossy and I'Il tell them to be quiet or, you know, "Not yet!" [laughs] "Wait!"...The fact that I've only been there for such a short time and they're already looking to me is quite complimentary, I guess. S10.9
\end{abstract}

The extent of the influence of informal choral team leaders, on morale and performance quality, is indicated by the effects of their absence as well as their presence:

In the male voice choir [...] they tend to get a bit lost, as we do in the second tenors [laughs], if we've got a few key people missing. S6.3

The absence of a strong lead can mean that the individual singers, or even whole sections of the choir, can lack confidence, or even entirely miss musical entries:

Oddly enough, at our concert... we completely missed our entry [laughs] and [conductor] looked at us as if to say, "Where the hell are you?" I don't know why, but we all just blanked out! [...] Subconsciously you're looking for your leader to come in, and it didn't happen! S11.21

The sense of security derived from a strong lead was compared with the feelings of unease and exposure that arise when a singer feels unsupported by neighbouring choir members:

Well, standing next to someone who you know is going to pitch the note right and come in at the right time is good for your confidence, 'cause you can sort of go along on their coat tails! But someone who just doesn't come in - I start to think, "Was I wrong? Can [the audience] only hear me?" S15.13

The findings presented here suggest that, for amateur singers, learning and confidence building are not unidirectional processes, flowing solely from interactions with the conductor. These processes have multidirectional characteristics, as they partly arise from the interactions between choir members, and the supportiveness (or otherwise) of the environment created by these interactions.

\title{
DISCUSSION
}

The majority of interviewees discussed the importance, in terms of both musical attainment and confidence building, of cohesion, collaboration, teamwork, and learning from other singers. This study demonstrates that effective peer learning, in a supportive choral environment, can assist task mastery, improve performance, and consequently help to 
develop higher levels of perceived self-efficacy. The participants described learning from fellow singers in a way that relates to the concept of situated learning (Lave and Wenger, 1991), in which peer learning can be interpreted in terms of a type of choral "apprenticeship" in which newcomers learn from "old timers", as seen in other organizational and educational contexts (Wenger 1998). The amateur choral environment can therefore be viewed as a form of community of practice, in which singers participate in shared learning and performance activities, and "build relationships that enable them to learn from each other" (Wenger, 2011, p. 2). Effective social learning, improvements in performance quality, and increases in individual and collective confidence are integral and interlinked facets of participation in the choral community of practice.

From the singers' perspective, it is clear that peer learning plays a strong part in many different types of amateur choir, regardless of the individual leadership style of the conductor. It is acknowledged that many choir leaders are already working with singers in a collaborative way, and prioritize creating a supportive environment in which multidirectional learning can take place. However, it is also recognized that this may not always be the case (Bonshor, 2017; Kreutz and Brünger, 2012) and that some reflection on facilitation processes may sometimes be necessary. This research illustrates the importance of peer interactions as an adjunct to the leadership and teaching provided by the conductor, and suggests that the discussed aspects of choral group dynamics may be even more significant to the singers than might have been expected.

This study has explored the needs of the singers, from their perspective, in order to facilitate confident learning and performance. From the findings, it is possible to extrapolate a few points for leaders of amateur choirs, which may support their existing practice or suggest areas for choir development. Firstly, it is important to recognize the benefits of peer-to-peer interactions so that they can be optimized during rehearsal and performance. Secondly, it is worth exploring ways of developing the choir's potential as an effective team. Conductors can clearly contribute to an environment in which trust and rapport can be developed, not only between themselves and the singers, but between all the individuals within the choir. Practical team building activities and collaborative warm-up exercises, social events and communal learning activities can contribute to this (Bonshor, 2018). Thirdly, it is helpful for conductors to take into account the varying confidence levels and competency of the choir members within their choral team, and to develop a flexible approach to encouraging and integrating singers with a range of different strengths and weaknesses. Further discussion of the possible applications of the research findings will be woven through the remainder of this paper.

The findings reported here make a connection between some of the seminal work on self-efficacy (Bandura, 1977) and show how this has practical implications in the choral context. Whilst this study was based on individual, subjective perceptions of personal efficacy, collective efficacy (Bandura, 2000) emerged as an important aspect of group singing, with its complex combination of musical and social challenges. Group efficacy is a perception that "resides in the minds of group members as the belief they have in common regarding their group's capability" (Bandura, 2006, p. 165), and has a strong influence on the confidence of the group as a whole, as well as upon individual self-efficacy. The current study suggests that this is the case in amateur choral settings. Participants commonly described the choir as a team, acknowledging that it is a unit which simultaneously consists 
of a collection of diverse individuals with differing confidence levels, experience, skills, backgrounds, needs, and potential contributions. The proficiency and confidence of other choir members, and the individual's evaluation of his or her own task mastery and perceived self-efficacy, were shown to have a reciprocal effect on each other.

Although group efficacy is largely derived from emergent, interactional processes, it has similar sources, functions, and consequences to personal efficacy beliefs (Bandura, 1997). Perceptions of personal efficacy and collective efficacy both affect motivation and effort, persistence in the face of opposition or obstacles, and the likelihood of discouragement (Bandura, 2000). Shared efficacy beliefs are also malleable, and can be affected by a number of factors, including personal mastery experiences, peer modelling, and trustworthy verbal encouragement (Bandura, 1977). In amateur choirs, there are opportunities for increasing self-efficacy through all three of Bandura's suggested mechanisms. Firstly, singers have the chance to acquire direct personal experience of choral learning and performing. Secondly, they observe and learn from the behavioural and musical examples provided by fellow singers. Thirdly, they receive verbal feedback, information and encouragement from their peers. The participants in this study reported that cohesion, trust and rapport amongst the singers are important pre-conditions for accepting support and encouragement, and for giving and receiving meaningful peer feedback. These interactions enable effective peer learning and the accumulation of mastery experiences, which has a positive effect on choral confidence.

Alongside reports of general musical and moral support, verbal encouragement, and experiences of peer learning amongst choir members, the participants in this study recognized that certain singers often emerged as unelected but influential team leaders. Although Wenger (1998) described meaningful learning relationships between "newcomers" and "old timers", the role of unofficial choral team leader is not always simply related to the individual's amount of relevant experience. Within amateur choirs, informal team leaders were often reported as being depended upon due to specific skills or characteristics, such as: having a strong voice or reliable intonation; demonstrating an ability to hold the melodic line or retain the harmony; being confident about starting notes and musical entries; displaying sight-reading proficiency; being willing to share musical knowledge; showing dependable recall of notes and lyrics. These attributes were deemed to be more important than the number of years of singing experience, or the amount of time spent in a particular choir.

The contribution of choral team leaders (in terms of sharing feedback, support and information, assisting in peer learning, and helping to optimize group performance), is generally seen as having a positive impact on the confidence levels of their fellow singers. In choral settings, the phenomenon of informal team leadership has previously been identified, largely in relation to practical and technical aspects of performance, such as intonation, timing and musical entries in high school choirs (Zadig, Folkestad, \& Åhlander Lyberg, 2017), and tackling the intricacies of unfamiliar or complex works in amateur choral societies (Einarsdottir, 2014). The current study demonstrates that informal choral team leaders also have a profound impact on affective aspects of rehearsing and performing in a wide range of amateur singing groups, including making a significant contribution to collective and individual choral confidence.

The identification of these unofficial choral team leaders appears to happen organically, 
as a result of social and musical interactions, and is based upon choir members' perceptions of their fellow singers' experience, performance quality, vocal and musical skills, and selfconfidence. Further investigation would be required to ascertain whether there are any potential advantages in more formally recognising the contribution of these team leaders. However, it may be the case that the emergence of unelected but informally acknowledged internal choral leaders is better left as a naturally occurring process, which happens as an intrinsic component of the development of choral communities. Nevertheless, it may be useful for conductors to take note of the role of the unofficial team leaders within their choirs, and to take this into account when deciding upon voice placement. Positive effects upon confidence can be achieved by placing stronger singers next to weaker singers, more skilled sight readers next to less accomplished readers, and more self-assured singers next to less confident performers.

\section{CONCLUSION}

It has previously been suggested that the collaborative model of the community of practice may usefully be applied to learning in musical settings, including professional vocal ensembles (Lim, 2014), symphony orchestras (Dobson \& Gaunt, 2014), and some aspects of music education:

\footnotetext{
The teacher leads the classroom in group improvisations, rather than acting as a solo "performer" in front of the class "audience". Students become socialized into classroom communities of practice, in which the whole class collaborates in each student's learning. (Sawyer, 2006, p. 163)
}

This can be applied within the amateur choir if the above quotation is adapted for the choral setting. In this case the conductor facilitates the choir's learning so that the singers may become socialized into choral communities of practice, in which the whole choir collaborates in each singer's learning (Bonshor, 2018).

Although a choir is not always viewed as a formal educational environment, "everything involved in rehearsing and conducting can be characterized by a teaching paradigm" (Price \& Byo, 2002, p. 336). The findings presented in this article indicate that some of the concepts related to the interactive social learning already being developed in classroom settings (see Green, 2005) are also applicable specifically to conducting amateur choirs. Recognising the multidirectional learning and the mutual emotional support within an adult amateur choir may be the first step towards re-interpreting the singer's role as an active agent rather than a passive learner, and more explicitly acknowledging their contribution to peer learning. Consequently, the conductor's role can be seen as a collaborator and facilitator, or "senior learner" (Thurman \& Welch, 2000), working alongside informal team leaders and other learners.

Based on the findings presented in this article, developing the amateur choir as a community of practice has potential for achieving the aims of building confidence and attaining optimal performance. For the choral singers, this approach can increase their confidence and competence, with positive effects upon their performance. For the conductor, an approach based on community, teamwork and social learning can lead to developing a style of choral leadership which is facilitative and empowering for the choir. This approach can also form the foundations of competent, confident and musically 
satisfying choral performances for everyone involved.

Finally, to return to the distinction between amateur singers and the music students who have featured in previous self-efficacy studies, some of the findings in the current study may be similar for both groups of performers, as they are all involved in regular group singing activities leading to public performances. However, there are likely to be some differences for the following reasons. Although some amateur singers perform to an extremely high standard, most have not received intensive formal training to the same extent as university and conservatoire students who are usually operating with the intention of becoming professional musicians. This means that amateur choral singers obviously fall into a different category of performer, as they are participating in group singing activities in their leisure time, usually for their own enjoyment rather than as part of a formal programme of professional development. Their motivations, expectations, skills and knowledge, social interactions and modes of learning are therefore likely to be different from those of advanced music students, or indeed professional musicians. Hence replicating this study with participants from outside the amateur choral world (i.e., focusing on the relationship between peer interactions and confidence levels amongst vocal students in Higher Education or professional singers) may produce different results from those presented here. However, for the amateur singers in this study, being part of a cohesive, collaborative team in which social learning takes place, can make an important contribution to their confidence levels when rehearsing and performing.

\section{REFERENCES}

Bailey, B. A., \& Davidson, J. W. (2002). Adaptive characteristics of group singing: Perceptions from members of a choir for homeless men. Musicae Scientiae, 6(2), 221-256.

Bailey, B. A., \& Davidson, J. W. (2005). Effects of group singing for marginalized and middleclass singers. Psychology of Music, 33(3), 269-03.

Bandura, A. (1977). Self-efficacy: Towards a unifying theory of behavioral change. Psychological Review, 84(2), 191-215.

Bandura, A. (1997). Self-efficacy: The Exercise of Control. New York: Freeman.

Bandura, A. (2000). Exercise of human agency through collective efficacy. Current Directions in Psychological Science, 9(3), 7578.

Bandura, A. (2006). Towards a psychology of human agency. Perspectives on Psychological Science, 1, 164-180.

Bandura, A., \& Cervone, D. (1986). Differential engagement of self-reactive influences in cognitive motivation. Organizational Behavior and Human Decision Processes, 38, 92113.

Beck, R., Cesario, T., Yousefi, S., \& Enamoto, H. (2000). Choral singing, performance perception and immune system changes in salivary immunoglobulin and cortisol. Music Perception, 18(1), 87-106.

Bogdan, R., \& Taylor, S. J. (1975). Introduction to Qualitative Research Methods: A Phenomenological Approach to the Social Sciences. New York: J. Wiley \& Sons, Inc.

Bong, M., \& Skaalvik, E. M. (2003). Academic self-concept and self-efficacy: How different are they really? Educational Psychology Review, 15(1), 1-40.

Bonshor, M. J. (2002). Musical performance anxiety amongst adult amateur singers: The 
effects of age, experience and training. Unpublished Master's dissertation. The University of Sheffield.

Bonshor, M. J. (2014). Confidence and the choral singer: The effects of choir configuration, collaboration and communication. Unpublished doctoral thesis. The University of Sheffield.

Bonshor, M. (2017). Conductor feedback and the amateur singer: The role of criticism and praise in building choral confidence. Research Studies in Music Education, 39(2), 139160.

Bonshor, M. J. (2018). The Confident Choir: A Handbook for Leaders of Group Singing. New York: Rowman and Littlefield International.

Corbin, J. and Strauss, A. (2008). Basics of Qualitative Research: Techniques and Procedures for Developing Grounded Theory. Thousand Oaks: Sage.

Bray, S. B. (2004). Collective efficacy, group goals, and group performance of a muscular endurance task. Small Group Research, 35, 230-238.

Clift S., \& Hancox, G. (2010). The significance of choral singing for sustaining psychological well-being: Findings from a survey of choristers in England, Australia and Germany. Music Performance Research, 3(1), 79-96.

Creech, A., Hallam, S., McQueen, H., \& Varvarigou, M. (2013). The power of music in the lives of older adults. Research Studies in Music Education, 35(1), 87-102.

Davidson, J. W. (1997). The social in musical performance. In A. North \& D. Hargreaves (Eds.), The Social Psychology of Music. (pp. 209-228). Oxford University Press.

Davidson, J. W., \& Burland, K. (2006). Musician identity formation. In G. McPherson (Ed.), The Child as Musician: A Handbook of Musical Development, (pp. 475-490). Oxford University Press.

Dingle, G. A., Brander, C., Ballantyne, J., \& Baker, F. A. (2013). To be heard: The social and mental health benefits of choir singing for disadvantaged adults. Psychology of Music, 41(4), 405-421.

Gaunt, H., \& Dobson, M. C. (2014). Orchestras as "ensembles of possibility": Understanding the experience of orchestral musicians through the lens of communities of practice. Mind, Culture, and Activity, 21(4), 298-317.

Eades, G., \& O'Connor, M. (2008). Sounds Lively! Choirs: Introducing singing into healthcare. The Journal of the Royal Society for the Promotion of Health, 128(2), 60-61.

Einarsdottir, S. L. (2014). "Leaders," "followers" and collective group support in learning "art music" in an amateur composer-oriented Bach Choir. British Journal of Music Education, 31(3), 281-296.

Falkenberg, I., Bartels, M., \& Wild, B. (2008). Keep smiling! Facial reactions to emotional stimuli and their relationship to emotional contagion in patients with schizophrenia. European Archives of Psychiatry and Clinical Neuroscience, 258, 245-253.

Faulkner, R. F., \& Davidson, J. W. (2006). Men in chorus: Collaboration and competition in homo-social vocal behaviour. Psychology of Music, 34, 219-237.

Frey, J. H., \& Fontana, A. (1991). The group interview in social research. In D. L. Morgan (Ed.), Successful Focus Groups: Advancing the State of the Art. (pp. 21-34). Newbury Park, CA: Sage.

Goodson, I. F., \& Sikes, P. (2001). Life History Research in Educational Settings: Learning from Lives. Open University Press. 
Green, L. (2005). Meaning, Autonomy and Authenticity in the Music Classroom. Institute of Education.

Greenlees, I. A., Graydon J. K., \& Maynard, I. W. (2000). The impact of individual efficacy beliefs on group goal commitment. Journal of Sports Sciences, 18, 451-459.

Greenlees, I. A., Nunn, R. L., Graydon, J. K., \& Maynard, I. W. (1999). The relationship between collective efficacy and precompetitive affect in rugby players: Testing Bandura's model of collective efficacy. Perceptual and Motor Skills, 89, 431-440.

Hendricks, K. S. (2014). Changes in self-efficacy beliefs over time: Contextual influences of gender, rank-based placement, and social support in a competitive orchestra environment. Psychology of Music, 42(3), 347-365.

Janesick, V. J. (2000). The choreography of qualitative research design: minuets, improvisations, and crystallization. In N. K. Denzin, \& Y. S. Lincoln, (Eds.), Handbook of Qualitative Research. (2nd Ed., pp. 379-400). Sage.

Judd, M., \& Pooley, J. A. (2014). The psychological benefits of participating in group singing for members of the general public. Psychology of Music, 42(2), 269-283.

Kreutz, G., Bongard, S., Rohrmann, S., Hodapp, V., \& Grebe, D. (2004). Effects of choir singing or listening on secretory immunoglobulin $A$, cortisol and emotional state. Journal of Behavioural Medicine, 27(6), 623-35.

Kreutz, G., \& Brünger, P. (2012). A shade of grey: Negative associations with amateur choral singing. Arts \& Health, 4(3), 230-238.

Lamont, A. (2002). Musical identities and the school environment. In R. A. R. MacDonald, D. J. Hargreaves, and D. E. Miell (Eds.), Musical identities (pp. 41-59). Oxford University Press.

Lamont, A. (2011): The beat goes on: Music education, identity and lifelong learning, Music Education Research, 13(4), 369-388.

Lamont, A., Hargreaves, D. J., Marshall, N. A. \& Tarrant, M. (2003). Young people's music in and out of school. British Journal of Music Education, 20, (3), 229-241.

Lave, J., And Wenger, E. (1991). Situated learning: Legitimate peripheral participation. Cambridge University Press.

Lim, M. C. (2014). In pursuit of harmony: The social and organisational factors in a professional vocal ensemble. Psychology of Music, 42(3) 307-324.

Luszczynska, A., Gutiérrez-Doña, B., \& Schwarzer, R. (2005). General self-efficacy in various domains of human functioning: evidence from five countries. International Journal of Psychology, 40(2), 80-89.

Madriz, E. (2000). Focus groups in feminist research. In N. K. Denzin \& Y. S. Lincoln (Eds.), Handbook of qualitative research (2nd Edition) (pp. 835-850). Sage.

Maykut, P., \& Morehouse, R. (1994). Beginning Qualitative Research: A Philosophic and Practical Guide. The Falmer Press.

McCormick, J., \& McPherson, G. (2003). The role of self-efficacy in musical performance examination: an exploratory structural equation analysis. Psychology of Music, 51(1), 37-51.

McPherson, G. E., \& McCormick, J. (2006). Self-efficacy and music performance. Psychology of Music, 34(3), 322-336.

Mellor, L. (2013). An investigation of singing, health and well-being as a group process. British Journal of Music Education, 30(2), 177-205. 
Murray, M., \& Lamont, A. (2012). Community music and social/health psychology: Linking theoretical and practical concerns. In R. A. R. MacDonald, G. Kreutz, and L. B. Mitchell (Eds.), Music, Health \& Wellbeing (pp. 76-86). Oxford University Press.

Nielsen, S. G. (2004). Strategies and self-efficacy beliefs in instrumental and vocal individual practice: A study of students in higher education. Psychology of Music, 32(4), 418-431.

Pajares, F. (1996). Self-efficacy beliefs in academic settings. Review of Educational Research, 66, 543-578.

Parker, E. C. (2010). Exploring student experiences of belonging within an urban high school choral ensemble: An action research study. Music Education Research, 12(4), 339-352.

Patton, M. J. (1991). Qualitative research on college students: philosophical and methodological comparisons with the quantitative approach. Journal of College Student Development, 32, 389-96.

Plummer, K. (2001). Documents of life 2. Sage.

Price, H. E., \& Byo, J. L. (2002). Rehearsing and conducting. In R. Parncutt, \& G. E. McPherson (Eds.), The Science and Psychology of Music Performance (pp. 269-283). Oxford University Press.

Radbourne, J., Johansson, K., Glow, H., \& White, T. (2009). The audience experience: Measuring quality in the performing arts. International Journal of Arts Management, 11(3), 16-29.

Ritchie, L., \& Williamon, A. (2011a). Measuring distinct types of musical self-efficacy. Psychology of Music, 39(3), 328-344.

Ritchie, L. \& Williamon, A. (2011b). Primary school children's self-efficacy for music learning. Journal of Research in Music Education, 59(2), 146-161.

Ruud, E. (2013). Can music serve as a 'cultural immunogen'? An explorative study. International Journal of Qualitative Studies on Health and Well-being, 8, (20597). http://dx.doi.org/10.3402/qhw.v8i0.20597

Sawyer, R. K. (2006). Group creativity: Musical performance and collaboration. Psychology of Music, 34(2), 148-165.

Sichivitsa, V. (2003). College choir members' motivation to persist in music: Application of the Tinto model. Journal of Research in Music Education, 5, 330-341.

Smith, J. A. (1995). Semi-structured interviewing. In J. A. Smith, R. Harre, L. Van Langenhove (Eds.), Rethinking Methods in Psychology (pp. 9-27). Sage.

Smith, J. A. (2004). Reflecting on the development of interpretative phenomenological analysis and its contribution to qualitative research in psychology. Qualitative Research in Psychology, 1, 39-54.

Smith, J. A., Flowers, P., \& Larkin, M. (2009). Interpretative phenomenological analysis. Sage Publications Ltd.

Smith, J. A. \& Osborn, M. (2003). Interpretative phenomenological analysis. In J. A. Smith (Ed.), Qualitative psychology: A practical guide to research methods (pp. 51-79). Sage.

Stebbins, R. A. (1996). The barbershop singer: Inside the social world of a musical hobby. University of Toronto Press.

Sundberg, J. (1987). The science of the singing voice. The Northern Illinois University Press.

Thurman, L., \& Welch, G. F. (2000). Bodymind and voice: Foundations of voice education (2nd ed.). lowa City: National Center for Voice and Speech.

Vealey, R. S., Hayashi, S. W., Garner-Holman, M., \& Giacobbi, P. (1998). Sources of sport- 
confidence: conceptualisation and instrument development. Journal of Sport Psychology, 20, 54-80.

Wenger, E. (1998). Communities of practice: learning, meaning and identity. Cambridge University Press.

Wenger, E. (2000). Communities of practice and social learning systems. Organization, 7(2), 225-246.

Wenger, E. (2011). Communities of practice: A brief introduction. Scholarsbank.uoregon.edu Zadig, S., Folkestad, G., \& Åhlander Lyberg, V. (2017). Choral singing under the microscope: Identifying vocal leaders through comparison of individual recordings of the singers. The Finnish Journal of Music Education (FJME) 20, 77-98.

DR MICHAEL BONSHOR has a background as a conductor and has published research on confidence building, wellbeing and musical leadership. He is Course Director for the University of Sheffield's MA Music Psychology in Education, Performance and Wellbeing, and Co-Investigator on the University of Derby's research on singing and mental health. 